\title{
Ligand Based in-silico Study on Pyridopyrimidinedione Derivatives as Dipeptidyl Peptidase-IV Inhibitors
}

\author{
Ghode Piyush, Jain Sanmati Kumar* \\ SLT Institute of Pharmaceutical Sciences, Guru Ghasidas Vishwavidyalaya, Bilaspur (Chhattisgarh), INDIA.
}

\begin{abstract}
Background: Type-2 diabetes mellitus can be effectively treated with dipeptidyl peptidaseIV inhibitors. Diverse classes of molecules have exhibited promising DPP-IV inhibition. Objective: In this perspective, 3D-QSAR and pharmacophore studies on a series of substituted pyridopyrimidinedione derivatives were performed to explore the structural requirements for effective DPP-IV inhibitory activity. Methods: 3D-QSAR was performed on 3D-QSAR module of Vlife molecular design suite (MDS) while two strategies were used for pharmacophore identification: MolSign module of MDS and Pharmagist. Results: The most significant 3D-QSAR models obtained from kNN and PLSR exhibited $79 \%$ and $77 \%$ of internal and $66 \%$ and $67 \%$ of external predictability respectively. The results from both kNN and PLSR models suggest the contribution of electronegative group with optimum bulk to be favourable for biological activity. Additional information about field point S_376 suggests a more bulky group to be favourable around S_376 at R1. The results from pharmacophore studies by both the strategies indicate the contribution of three hydrogen bond acceptors, one hydrogen bond donor and one aromatic feature for biological activity. Conclusion: Findings of the present study can be utilized for development of new lead compounds exhibiting promising DPP-IV inhibitory activity.

Key words: DPP-IV, 3D-QSAR, kNN, Pharmacophore, Pharmagist.
\end{abstract}

\section{INTRODUCTION}

Dipeptidyl peptidase-IV (DPP-IV, CD26, EC 3.4.14.5) is one of the validated targets for drugs deployed in the management of type-2 diabetes mellitus (T2DM). Since the last decade with the launch of sitagliptin, ${ }^{1}$ the DPP-IV inhibitors have been used as an alternative as well as in combination with other existing drugs for effective blood glucose control. ${ }^{2}$ DPP-IV finds its major role in inactivation of the incretin hormones glucagon like peptide-1 (GLP-1) and glucose inhibitory peptide (GIP) involved in initiation of the insulin secretion cascade following a meal. The enzyme is a serine protease which truncates GLP-1 resulting in infinitesimal half-life of the hormones. Thus, inhibition of DPP-IV results in an increase in half-life of incretin hormones and eventually in augmentation of insulin secretion. ${ }^{3,4}$

DPP-IV inhibitors belong to an assortment of chemical classes. These can be classified in different ways, e.g. natural and synthetic orpeptidomimetics and non peptidomimetics. Peptidomimetics mimic the penultimate dipeptide structure of DPP-IV substrate and can again be sub-classified as glycine or $\beta$-alanine derivatives. Non peptidomimetic inhibitors do not follow dipeptide structure of DPP-4 substrate and were developed through high-throughput screening (HTS). ${ }^{5}$ The marketed DPP-IV inhibitors belong to both peptidomimetic (vildagliptin and saxagliptin) and non-peptidomimetic classes (sitagliptin, alogliptin and linagliptin). ${ }^{6}$ Pyridopyrimidinediones have
Submission Date: 17-10-2016; Revision Date: 14-03-2017; Accepted Date: 13-07-2017

DOI: 10.5530/ijper.51.4.98 Correspondence: Dr. Jain Sanmati Kumar, Associate Professor, SLT Institute of Pharmaceutical Sciences, Guru Ghasidas Vishwavidyalaya, Bilaspur (Chhattisgarh), INDIA. Phone numbers: 07752260027

Facsimile numbers: $07752-$ 260148

E-mail: sanmatijain72@ yahoo.co.in

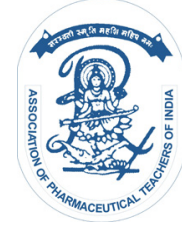

www.ijper.org 
been investigated for various biological activities such as anticancer, phospodiesterase-4 inhibitory and herbicidal activities. ${ }^{7-9}$ Lam et al. reported pyridopyrimidinedione derivatives as potent and selective non-covalent inhibitors of DPP-IV. ${ }^{10}$

Quantitative structure activity relationship (QSAR) study has established itself as one of the imperative ligand based drug design methods. It is a rational approach of finding relationship between biological activities of compounds and numerical representations of molecular properties (descriptors). Depending upon the descriptor type (physicochemical, structural and conformational properties) QSAR can be classified as one dimensional (1D), 2D, 3D, 4D, 5D and 6D. Among these 2D and 3D QSAR studies are more frequent. Whereas the 2D QSAR involves descriptors correlating activity with structural patterns like connectivity indices, 2D-pharmacophores etc., without taking into account the 3D-representation of these properties; 3D QSAR involves descriptors correlating activity with non-covalent interaction fields surrounding the molecules. ${ }^{11} \mathrm{~A}$ pharmacophore is the special arrangement of features that enables a molecule to interact with a target receptor in a specific binding mode. Once identified, a pharmacophore can serve as a powerful model in versatile applications for rational drug design such as virtual screening, de novo design, lead optimization and ADMET studies. ${ }^{12}$ The present investigation encompasses 3D QSAR and pharmacophore study of some pyridopyrimidinedione derivatives in an attempt to determine the structural features for improved DPP-IV inhibition.

\section{MATERIALS AND METHODS}

QSAR analysis was performed by k-nearest neighbour molecular field analysis ( $k N N-M F A)$ and partial least squares regression (PLSR) employed in Vlife molecular design suite (Vlife MDS) on HCL computer with Intel Pentium Dual Core processor and a Windows XP operating system. ${ }^{13,14}$ A data set of 20 pyridopyrimidinedione derivatives with DPP-IV inhibitory activity spanning three $\log$ values was chosen from the work of Lam et al. ${ }^{10}$ The $\mathrm{IC}_{50}$ values were converted to the negative logarithmic scale $\left[\mathrm{pIC}_{50}\right.$ (moles)] (Table 1).

\section{Molecular modelling}

Compound structures were drawn using the $2 \mathrm{D}$ draw application of MDS and converted to 3D. Optimization of molecular structures was performed by molecular mechanics using Merck molecular force field (MMFF), ${ }^{15}$ setting electrostatic and steric energies to default values of 30.0 and $10.0 \mathrm{Kcal} /$ mole as cut off. These energy minimized structures were aligned using template based alignment (Figure 1) and electrostatic, steric and hydrophobic fields were calculated on a rectangular grid surrounding the molecules using a $\mathrm{sp}^{3}$ hybridized carbon atom as a probe.

\section{Creation of training and test sets}

In order to perceive the ability of the model to predict the activity of compounds not included in its development (external validation), the data set was divided into training and test sets. Random selection method was used for division of the data set into training set $(80 \%)$ and test set $(20 \%)$.

\section{Model validation}

The generated QSAR models were subjected to internal and external validation to adjudge their goodness-of-fit and predictivity respectively. Some examples for internal validation are leave-one-out (LOO) cross validation $\left(q^{2}\right)$, leave-many-out (LMO) cross validation $\left(\mathrm{LMO}-q^{2}\right)$, bootstrapping (Boot- $\left.q^{2}\right),{ }^{16}$ True $q^{2}$ and the $r_{m}{ }^{2}$ metric for internal validation etc., ${ }^{17,18}$ while for external validation predicted $r^{2}$ (or $\left.q_{(F 1)}^{2}\right), q_{(F 2)}^{2}{ }^{19} q_{(F 3)}^{2}{ }^{20}$ Golbraikh and Tropsha's criteria, ${ }^{21} r_{m \text { (test) }}^{2}$ and concordance correlation coefficient (CCC) etc. can be used. ${ }^{22}$

The internal validation of QSAR models was performed by calculation of leave-one-out (LOO) cross validation $\left(q^{2}\right)$ by equation 1 .

$$
q^{2}=1-\frac{\sum\left(y_{i}-\hat{y}_{i}\right)^{2}}{\sum\left(y_{i}-\bar{y}_{i}\right)^{2}}
$$

Where $y_{i}$ and $\hat{y}_{i}$ are the actual and predicted activities of the $i$ th compound, respectively, and $\bar{y}_{l}$ is the average activity of all compounds in the training set.

While performing external validation, the predictivity of a model can be judged by the value of pred_ $r^{2}$ which reflects the degree of correlation of observed and predicted activities. Different formulae for calculation of pred_ $r^{2}$ have been suggested by various research groups. Among these the most widely used formula is given in equation 2 .

$$
\text { Pred } \_r^{2}=1-\frac{\sum\left(y_{\text {prad (tort })}-y_{(\text {tst })}\right)^{2}}{\sum\left(y_{\text {tost }}-\bar{y}_{\text {trining }}\right)^{2}}
$$

The robustness of the models was confirmed by Y-randomization. For this purpose response variables in the data set were scrambled and random models were generated with this data. $Z$ score and probability $(\alpha)$ of significance of randomization were calculated to ascertain that there is no chance correlation. $\mathrm{Z}$ score repre- 
sents the distance between a parameter calculated from a model and the mean score of that parameter from all the randomized models in units of standard deviation. $\mathrm{Z}$ score value was calculated by the following formula:

$$
Z \text { score }=\frac{(h-\mu)}{\sigma}
$$

Where $b$ is the $q^{2}$ value calculated for the actual dataset, $\mu$ and $\sigma$ are the average $q^{2}$ and the standard deviation of random models respectively. The values for $Z$ score $r^{2}$ and $\mathrm{Z}$ score pred_r $\mathrm{r}^{2}$ can also be calculated accordingly. The probability $(\alpha)$ of significance of randomization test can be derived by comparing $Z$ score with $Z$ score critical value as reported in reference tables if $Z$ score value is less than 4.0 ; otherwise it can be calculated by the following formula (equation 4 ). ${ }^{23}$

$$
\alpha=\left\{1 /\left[\sigma(2 \pi)^{1 / 2}\right]\right\} e^{-z^{2} / 2}
$$

\section{Pharmacophore studies}

Two strategies were applied for pharmacophore studies. In the first strategy, MolSign module of VLife MDS was used for the identification, generation and analysis of pharmacophores by alignment of the molecules on the basis of their 3D pharmacophore features. Different combinations of the pharmacophore features, tolerance limit and maximum distance were used. In the second strategy, the pharmacophoric features were generated with the aid of a web based freely available pharmacophore identification server Pharmagist. The data was uploaded in the form of a zip file to the server and all the settings were kept as default. In Pharmagist, the pharmacophore is constructed using six different features (H-bond acceptor, H-bond donors, aromatic centers, hydrophobic centers, negative charge and positive charge).

\section{RESULTS AND DISCUSSION}

DPP-IV inhibition is amongst the validated strategies for rational drug design in management of T2DM. Some pyridopyrimidinedione derivatives have been found to possess appreciable DPP-IV inhibitory activity. The present study is an attempt to establish 3D QSAR between structural features of such compounds and DPP-IV inhibition. The variables for QSAR model generation were selected by stepwise forward backward method. The statistical parameters of two most significant models developed by kNN and PLSR methods respectively suggest their internal and external predictive ability (Table 2). The developed models were also verified for their robustness via $\mathrm{Y}$ randomization. The values of
$\mathrm{Z}$ score and $\alpha$ for $\mathrm{r}^{2}, \mathrm{q}^{2}$ and pred_ $\mathrm{r}^{2}$ suggest that the models are robust and not obtained by chance correlation.

\section{Model 1}

$\mathrm{k}$ Nearest Neighbor $=2, N_{\text {training }}=16, N_{\text {test }}=4$, Degree of freedom $=19, \mathrm{q}^{2}=0.7850, \mathrm{q}^{2} \_\mathrm{se}=0.4354$, Pred_r $\mathrm{r}^{2}$ $=0.6650$, pred_r $\mathrm{r}^{2} \mathrm{se}=0.3361$

This model was developed using stepwise forward backward variable selection and has $\sim 79 \%$ of internal and $67 \%$ external predictivity. It depicts the influence of electrostatic field at E_312 and streric field at S_515 (Figure 2). The negative range of E_312 evinces the favourable effect of electronegative groups towards the biological activity while the negative range of S_515 expresses that the substituent with lower steric bulk has favourable effect on the biological activity and vice-versa. The low values of standard errors in internal $\left(\mathrm{q}^{2}\right)$ and external (pred_r $\mathrm{r}^{2}$ ) validation also suggest that the model has good predictive power. The graph for observed vs. predicted activity and their comparison are given in Figure 3.

\section{Model 2}

$$
\begin{aligned}
& \mathrm{pIC}_{50}=-63.9497-356.038 \mathrm{~S} \_157+20.5126 \mathrm{~S} \_376+ \\
& 3.19266 \mathrm{E} \_866 \\
& N_{\text {training }}=16, N_{\text {test }}=4, r^{2}=0.8455, q^{2}=0.7716, q^{2} \_\mathrm{se} \\
& =0.4507, \text { Pred_r } r^{2}=0.6716, \text { Pred_ } r^{2} \mathrm{se}=0.4524
\end{aligned}
$$

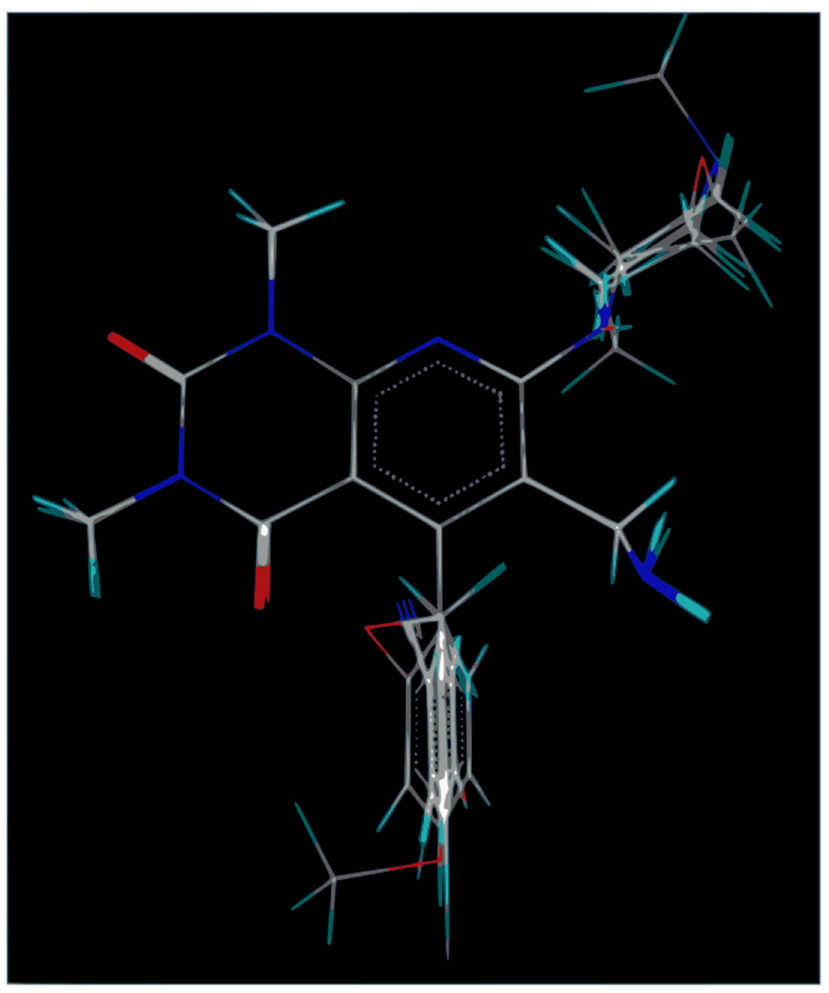

Figure 1: Alignment of all the molecules on the common template 


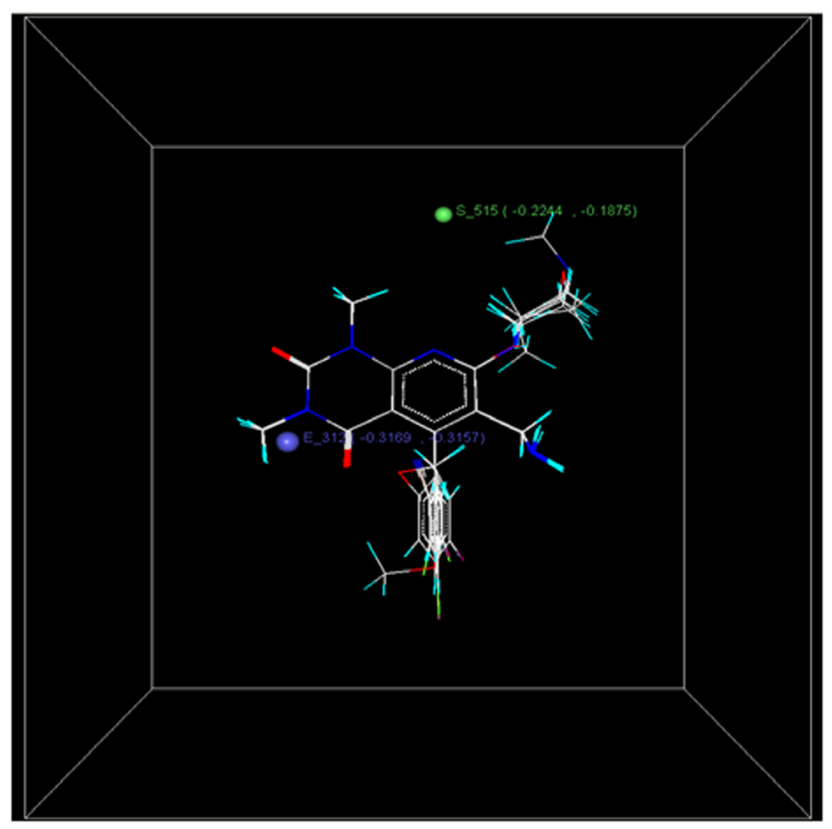

Figure 2: Contribution 3D-plot for Model-1 (Developed by kNN)

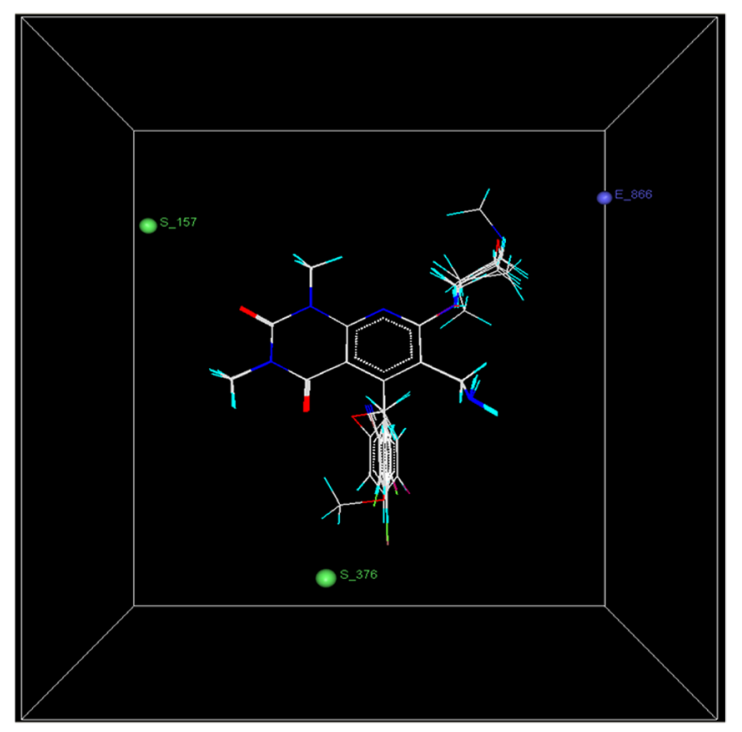

Figure 4: Contribution 3D-plot for Model-2 (Developed by PLSR).

The test set for this model was selected by stepwise forward backward variable selection. This model's internal prognostic ability is $\sim 77 \%$ and external predictivity is $\sim 67 \%$. It entails a negative contribution of $\mathrm{S} \_157$ towards favourable biological activity while owing to their positive coefficients conduciveness of a more bulky group around S_376 and a more electronegative group around E_866 (Figure 4). The Z-values for $\mathrm{r}^{2}, \mathrm{q}^{2}$ and pred_r $\mathrm{r}^{2}$ (3.78596, 2.41878 and 0.74517 respectively) show that the model is robust and not obtained by

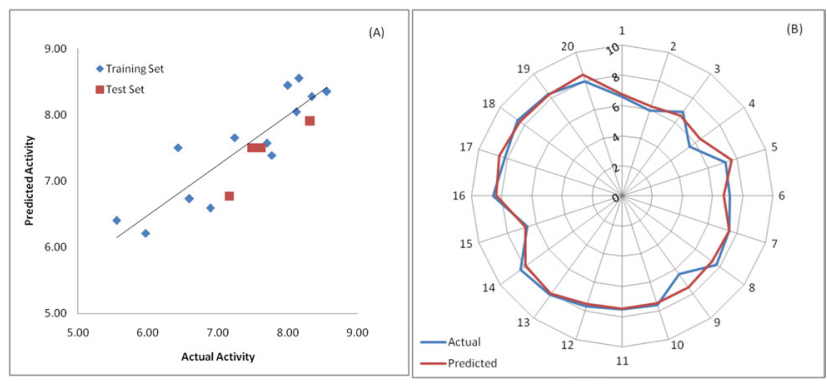

Figure 3: (a) Graph of observed vs. predicted activities for Model-1 (b) Comparison of actual and predicted activities for all the compounds for the same model (blue line: actual activity, red line: predicted activity).

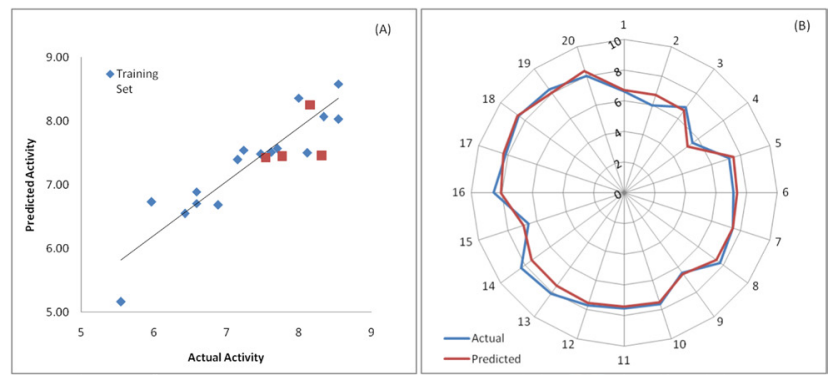

Figure 5: (a) Graph of observed vs. predicted activities for Model-2 (b) Comparison of actual and predicted activities for all the compounds for the same model (blue line: actual activity, red line: predicted activity).

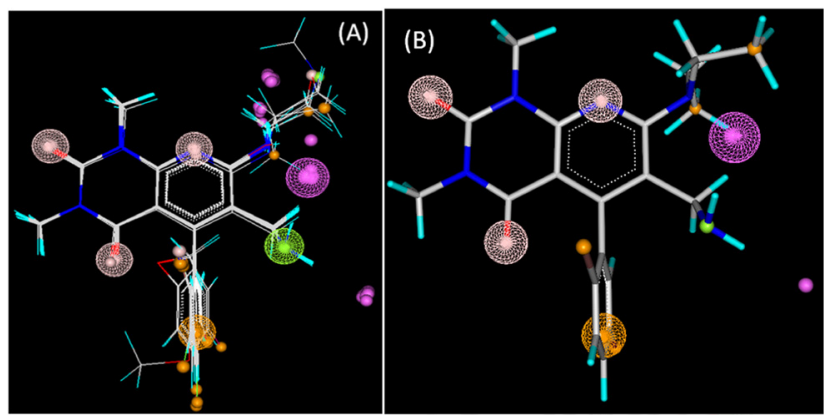

Figure 6: (a) Alignment of All the Molecules on the Common Pharmacophoric Features (b) The Most Active Molecule Aligned on the Pharmacophore.

chance. The corresponding values suggested a confidence interval of $>99 \%$. The graph for observed vs. predicted activity and their comparison for model 2 are given in Figure 5.

\section{Interpretation of pharmacophore identification:}

Based on the alignment of molecules presented in Table 1, different chemical feature based pharmacophore models were constructed with MolSign and Pharmagist. Different biophores were developed using various 


\section{Table 1: The Dataset Used for Development of QSAR}<smiles>[R]c1cccc(-c2c(CN)c(N)nc3c2c(=O)n(C)c(=O)n3C)c1</smiles>

Comp. 3a-3n<smiles>[R7]c1nc2c(c(-c3cc(F)ccc3Br)c1CN)c(=O)n(C)c(=O)n2C</smiles>

Comp. 10a-10f

\begin{tabular}{|c|c|c|c|c|c|c|c|}
\hline \multirow[b]{2}{*}{ Comp. No. } & \multirow{2}{*}{$\begin{array}{l}\text { Substitution } \\
\qquad\left(R / R_{1}\right)\end{array}$} & \multirow{2}{*}{$\begin{array}{l}I_{50} \\
(\mathrm{~nm})\end{array}$} & \multirow{2}{*}{$\begin{array}{l}\text { Actual } \\
\text { plC }_{50}\end{array}$} & \multicolumn{2}{|c|}{ Model -1 } & \multicolumn{2}{|c|}{ Model -2 } \\
\hline & & & & $\begin{array}{l}\text { Predicted } \\
\text { plC }_{50}\end{array}$ & Residual & $\begin{array}{l}\text { Predicted } \\
\text { plC }_{50}\end{array}$ & Residua \\
\hline $3 a$ & $\mathrm{H}$ & 257 & 6.59 & 6.73 & -0.14 & 6.71 & -0.12 \\
\hline $3 b$ & $4-\mathrm{F}$ & 1070 & 5.97 & 6.21 & -0.24 & 6.73 & -0.76 \\
\hline $3 c$ & $4-\mathrm{Br}$ & 128 & 6.89 & 6.59 & 0.30 & 6.69 & 0.20 \\
\hline $3 d$ & 3-OMe & 2800 & 5.55 & 6.40 & -0.85 & 5.16 & 0.39 \\
\hline $3 e$ & 2-OMe & 57 & 7.24 & 7.66 & -0.42 & 7.54 & -0.30 \\
\hline $3 f$ & $2-\mathrm{CN}$ & 69 & 7.16 & $6.77^{*}$ & 0.39 & 7.40 & -0.24 \\
\hline $3 g$ & $2-\mathrm{Cl}$ & 33 & 7.48 & $7.50^{*}$ & -0.02 & 7.48 & 0.00 \\
\hline $3 \mathrm{~h}$ & $2-\mathrm{Br}$ & 17 & 7.77 & 7.39 & 0.38 & $7.44^{*}$ & 0.33 \\
\hline $3 i$ & 2,3-di-Cl & 371 & 6.43 & 7.50 & -1.07 & 6.55 & -0.12 \\
\hline $3 j$ & 2,4-di-Cl & 24 & 7.62 & $7.51^{*}$ & 0.11 & 7.51 & 0.11 \\
\hline $3 \mathrm{k}$ & 2,5-di-Cl & 29 & 7.54 & 7.51 & 0.03 & $7.43^{*}$ & 0.11 \\
\hline 31 & 2-OMe, 5-F & 20 & 7.70 & 7.57 & 0.13 & 7.57 & 0.13 \\
\hline $3 m$ & 2-Cl, 5-F & 7.6 & 8.12 & 8.04 & 0.08 & 7.50 & 0.62 \\
\hline $3 n$ & $2-\mathrm{Br}, 5-\mathrm{F}$ & 4.8 & 8.32 & $7.90^{*}$ & 0.42 & $7.45^{*}$ & 0.87 \\
\hline $10 a$ & $\mathrm{OH}$ & 260 & 6.59 & 6.74 & -0.15 & 6.89 & -0.30 \\
\hline $10 \mathrm{~b}$ & $\mathrm{NHMe}$ & 2.8 & 8.55 & 8.35 & 0.20 & 8.03 & 0.52 \\
\hline $10 \mathrm{c}$ & NHEt & 6.9 & 8.16 & 8.55 & -0.39 & 8.26 * & -0.10 \\
\hline $10 d$ & $N(E t)_{2}$ & 2.8 & 8.55 & 8.35 & 0.20 & 8.59 & -0.04 \\
\hline $10 \mathrm{e}$ & morpholine & 4.6 & 8.34 & 8.28 & 0.06 & 8.07 & 0.27 \\
\hline $10 f$ & 1-Me-piperazine & 9.9 & 8.00 & 8.44 & -0.44 & 8.36 & -0.36 \\
\hline
\end{tabular}

* Test set molecules

combinations of features and tolerance limits. Both the pharmacophore identification strategies present three hydrogen bond acceptors, one hydrogen bond donor and one aromatic feature as common pharmacophoric features. The orange sphere in MolSign result represents aromatic, buff spheres represent hydrogen bond acceptors and magenta sphere represents hydrogen bond donor feature (Figure 6). In Pharmagist, green spheres represent hydrogen bond acceptors, sky-blue spheres represent aromatic and gray spheres represent hydrophobic features (Figure 7). The Pharmacophore Features of the Biophores for Different Combinations Using Both Molsign and Pharmagist are given in Table 3. 


\begin{tabular}{|c|c|c|c|c|}
\hline Parameters & \multicolumn{2}{|c|}{ kNN-MFA } & \multicolumn{2}{|c|}{ PLSR } \\
\hline $\begin{array}{c}\text { Training set } \\
\text { size (n) }\end{array}$ & \multicolumn{2}{|c|}{16} & \multicolumn{2}{|c|}{16} \\
\hline Test set size & \multicolumn{2}{|c|}{4} & \multicolumn{2}{|c|}{4} \\
\hline $\begin{array}{l}\text { K nearest } \\
\text { neighbour/ } \\
\text { Optimum } \\
\text { components } \\
\text { (PLSR) }\end{array}$ & \multicolumn{2}{|c|}{2} & \multicolumn{2}{|c|}{1} \\
\hline $\begin{array}{l}\text { Degree of } \\
\text { freedom }\end{array}$ & \multicolumn{2}{|c|}{19} & \multicolumn{2}{|c|}{14} \\
\hline$r^{2 \#}$ & \multicolumn{2}{|c|}{ - } & \multicolumn{2}{|c|}{0.8455} \\
\hline$q^{2}$ & \multicolumn{2}{|c|}{0.7850} & \multicolumn{2}{|c|}{0.7716} \\
\hline F-test ${ }^{\#}$ & \multicolumn{2}{|c|}{ - } & \multicolumn{2}{|c|}{76.6377} \\
\hline $\mathrm{r}^{2} \mathrm{se}^{\#}$ & \multicolumn{2}{|c|}{ - } & \multicolumn{2}{|c|}{0.3706} \\
\hline$q^{2}$ se & \multicolumn{2}{|c|}{0.4354} & \multicolumn{2}{|c|}{0.4507} \\
\hline Pred_r $r^{2}$ & \multicolumn{2}{|c|}{0.6650} & \multicolumn{2}{|c|}{0.6716} \\
\hline Pred_r $r^{2}$ se & \multicolumn{2}{|c|}{0.3361} & \multicolumn{2}{|c|}{0.4524} \\
\hline Z-score & \multicolumn{2}{|c|}{ - } & $\begin{array}{c}r^{2} \\
q^{2} \\
\text { Pred_r } r^{2}\end{array}$ & $\begin{array}{l}3.78596 \\
2.41878 \\
0.74517\end{array}$ \\
\hline $\begin{array}{l}\text { Descriptors } \\
\text { range/ } \\
\text { contribution }\end{array}$ & $\begin{array}{l}\text { E_312 } \\
\text { S_515 }\end{array}$ & $\begin{array}{l}(-0.3169 \\
-0.3157) \\
(-0.2244 \\
-0.1875)\end{array}$ & $\begin{array}{l}\text { S_157 } \\
\text { S_376 } \\
\text { E_866 }\end{array}$ & $\begin{array}{l}50.87 \% \\
12.66 \% \\
15.48 \%\end{array}$ \\
\hline
\end{tabular}

"Calculated only for PLSR model

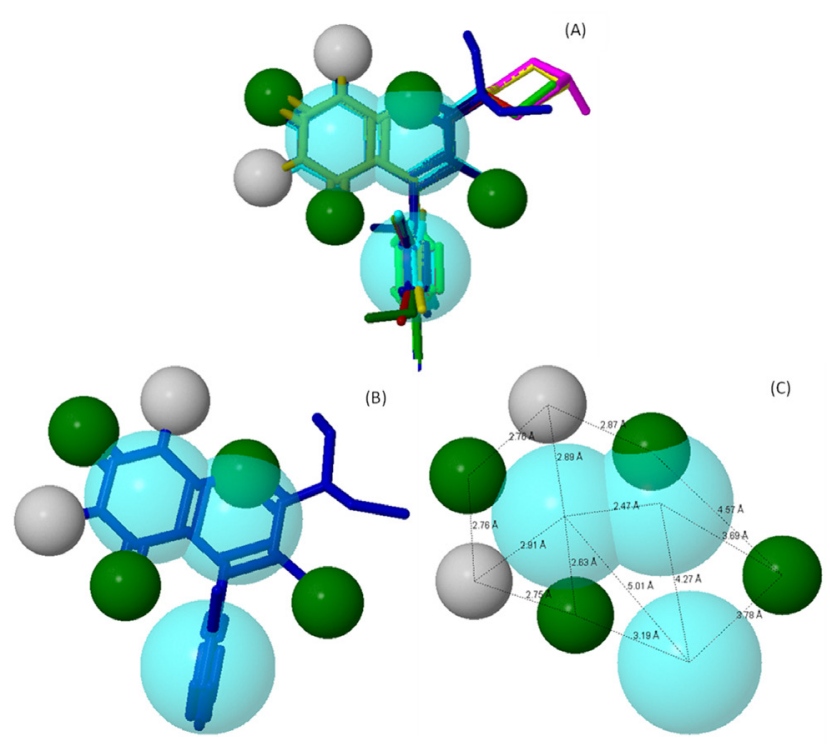

Figure 7: (a) Alignment of All the Molecules on Common Pharmacophore Features in Pharmagist (b) Position of the Pharmacophore Features on the Most Active Molecule (c) Distance Constraints Between Common Features of the Pharmacophore (Color Scheme: Sky blue-Aromatic, GreenHydrogen Bond Acceptor, Yellow-Hydrogen Bond Donor)

\begin{tabular}{|c|c|c|c|c|c|c|c|}
\hline $\begin{array}{l}\text { Combination } \\
\text { (Molsign)\# }^{\#}\end{array}$ & $\begin{array}{c}\text { Primary } \\
\text { pharmacophore } \\
\text { feature count }{ }^{\#}\end{array}$ & $\begin{array}{c}\text { Tolerance } \\
(\%)^{\#}\end{array}$ & $\begin{array}{c}\text { Maximum } \\
\text { distance } \\
\text { allowed }(\hat{A})^{\#}\end{array}$ & $\begin{array}{l}\text { Total } \\
\text { Number of } \\
\text { biophores } \\
\text { generated }\end{array}$ & $\begin{array}{l}\text { Biophore } \\
\text { with better } \\
\text { RMSD/ } \\
\text { score }\end{array}$ & Features & $\begin{array}{l}\text { RMSD(Mol- } \\
\text { sign)/Score } \\
\text { (Pharmagist) }\end{array}$ \\
\hline \multicolumn{8}{|c|}{ Molsign } \\
\hline$A$ & 3 & 20 & 10 & 332 & Bio-phore-2 & $\begin{array}{c}\text { HAc, HAc, PosC, } \\
\text { HAc, HDr }\end{array}$ & 0.054312 \\
\hline B & 5 & 20 & 10 & 225 & Bio-phore-1 & $\begin{array}{l}\text { HDr, HAc, HAc, } \\
\text { HAc, PosC, AroC }\end{array}$ & 0.097592 \\
\hline \multicolumn{8}{|c|}{ Pharmagist } \\
\hline- & - & - & - & 1 & 1 & $\begin{array}{l}\text { Aromatic (3), } \\
\text { Hydrophobic } \\
\text { (2), Donor (1), } \\
\text { Acceptors (4) }\end{array}$ & 75.71 \\
\hline
\end{tabular}

(The values in parentheses indicate the percentage of molecules aligned on the common pharmacophore features) 


\section{CONCLUSION}

Combating the prevailing diseases such as T2DM calls for efforts from all over the world to bring forth newer scaffolds targeting different receptors. These scaffolds can further be optimized for improved efficacy. To this end some pyridopyrimidine derivatives were investigated through ligand based drug design for improvement in their DPP-IV inhibitory potential. The results from $\mathrm{kNN}$ and PLSR models suggest the contribution of electronegative groups with optimum bulk to be favourable for biological activity. Additional information about field point S_376 anticipates a more bulky group at $\mathrm{R}_{1}$. Pharmacophore studies from both strategies envisage the contribution of three hydrogen bond acceptors, one hydrogen bond donor and one aromatic feature for biological activity. The findings of this study can be explored for improved DPP-IV inhibitors and further efforts in this direction are in progress.

\section{ACKNOWLEDGEMENT}

The authors wish to thank the Head of the Department, SLT Institute of Pharmaceutical Sciences for providing the necessary facilities to carry out the present research work.

\section{CONFLICT OF INTEREST}

The authors declare that there is no conflict of interest.

\section{ABBREVIATION USED}

ADMET: Absorption, distribution, metabolism, excretion and toxicity; CCC: Concordance correlation coefficient; DPP-IV: Dipeptidyl peptidase-IV; GIP: Glucose inhibitory peptide; GLP: Glucagon like peptide; HTS: High throughput screening; kNN-MFA: k-nearest neighbour molecular field analysis; LMO: Leave many out; LOO: Leave one out; MDS: Molecular design suite; PLSR: Partial least square regression; QSAR: Quantitative structure activity relationship; T2DM: Type-2 diabetes mellitus.

\section{REFERENCES}

1. Rosenstock J, Brazg R, Andryuk PJ, Lu K, Stein P, et al. Efficacy and safety of the dipeptidyl peptidase-4 inhibitor sitagliptin added to ongoing pioglitazone therapy in patients with type 2 diabetes: a 24-week, multicenter, randomized, double-blind, placebo-controlled, parallel-group study. Clinical therapeutics. 2006 Oct 1;28(10):1556-68. https://doi.org/10.1016/j.clinthera.2006.10.007; PMid:17157112.

2. Deacon CF. Dipeptidyl peptidase-4 inhibitors in the treatment of type 2 diabetes: a comparative review. Diabetes, Obesity and Metabolism. 2011; 13(1):7-18. https://doi.org/10.1111/j.1463-1326.2010.01306.x; PMid:21114598.

3. Ehses JA, Casilla VR, Doty T, Pospisilik JA, Winter KD, et al. Glucosedependent insulin tropic polypeptide promotes $\beta$-(INS-1) cell survival via cyclic adenosine monophosphate-mediated caspase- 3 inhibition and regulation of p38 mitogen-activated protein kinase. Endocrinology. 2003;144(10):4433-45. https://doi.org/10.1210/en.2002-0068; PMid:12960055.

4. Farilla L, Bulotta A, Hirshberg B, Li Calzi S, Khoury N, Noushmehr H, et al. Glucagon-like peptide 1 inhibits cell apoptosis and improves glucose responsiveness of freshly isolated human islets. Endocrinology 2003; 144 : 5149-5158. https://doi.org/10.1210/en.2003-0323; PMid:12960095.

5. Patel BD, Ghate MD. Recent approaches to medicinal chemistry and therapeutic potential of dipeptidyl peptidase-4 (DPP-4) inhibitors. European journal of medicinal chemistry. 2014;74:574-605. https://doi.org/10.1016/j. ejmech.2013.12.038 PMid:24531198

6. Pei Z. From the bench to the bedside: dipeptidyl peptidase IV inhibitors, a new class of oral antihyperglycemic agents. Current opinion in drug discovery \& development. 2008;11(4):512-32. PMid:18600568

7. Dong $Q$, Dougan DR, Gong X, Halkowycz P, Jin B, et al. Discovery of TAK733, a potent and selective MEK allosteric site inhibitor for the treatment of cancer. Bioorganic \& medicinal chemistry letters. 2011;21(5):1315-9. https:// doi.org/10.1016/j.bmcl.2011.01.071; PMid:21310613.

8. Tomkinson A, Karlsson JA, Raeburn D. Comparison of the effects of selective inhibitors of phosphodiesterase types III and IV in airway smooth muscle with differing $\beta$-adrenoceptor subtypes. British journal of pharmacology. 1993; 108(1):57-61. https://doi.org/10.1111/j.1476-5381.1993.tb13439.x;PMid:8428213 PMCid:PMC1907714.

9. Compton E, Cooke A, Jacobs R. Method of Controlling Plant Growth with 3-Substituted-Pyrido \{8 3,2-D\{9 Pyrimidine-2,4-(1h,3h)-Diones $\}$, US Patent, 3836351, sep 17, 1974.

10. Lam B, Zhang Z, Stafford JA, Skene RJ, Shi L, Gwaltney SL. Structurebased design of pyridopyrimidinediones as dipeptidyl peptidase IV inhibitors. Bioorganic \& medicinal chemistry letters. 2012;22(21):6628-31. https://doi. org/10.1016/j.bmcl.2012.08.110; PMid:23025999.

11. Verma J, Khedkar VM, Coutinho EC. 3D-QSAR in drug design-a review. Current topics in medicinal chemistry. 2010;10(1):95-115. https://doi. org/10.2174/156802610790232260; PMid:19929826.

12. Schneidman-Duhovny D, Dror O, Inbar $\mathrm{Y}$, Nussinov $\mathrm{R}$, Wolfson HJ. PharmaGist: a webserver for ligand-based pharmacophore detection. Nucleic acids research. 2008 Jul 1;36(suppl 2):W223-8. https://doi.org/10.1093/nar/ gkn187; PMid:18424800 PMCid:PMC2447755.

13. Ajmani S, Jadhav K, Kulkarni SA. Three-dimensional QSAR using the k-nearest neighbor method and its interpretation. Journal of chemical information and modeling. 2006 ;46(1):24-31. https://doi.org/10.1021/ ci0501286; PMid:16426036.

14. VLife MDS 3.5. VLife Sciences Technologies Pvt. Ltd., Pune India, 2008; software available at http://www.vlifesciences.com.

15. Halgren TA. Merckmolecular force field. I. Basis, form, scope, parameterization, and performance of MMFF94. Journal of computational chemistry. 1996;17(5-6):490-519. https://doi.org/10.1002/(SICI)1096-987X(199604)17: 5/6<490::AID-JCC1>3.0.CO;2-P; https://doi.org/10.1002/(SICI)1096-987X (199604)17:6<490::AID-JCC1>3.3.CO;2-V.

16. Wehrens R, Putter H, Buydens LM. The bootstrap: a tutorial. Chemometrics and intelligent laboratory systems. 2000;54(1):35-52. https://doi.org/10.1016/ S0169-7439(00)00102-7.

17. Hawkins DM, Basak SC, Mills D. Assessing model fit by cross-validation. Journal of chemical information and computer sciences. 2003;43(2):579-86. https://doi.org/10.1021/ci025626i; PMid:12653524.

18. Roy K, Mitra I, Kar S, Ojha PK, Das RN, et al. Comparative studies on some metrics for external validation of QSPR models. Journal of chemical information and modeling. 2012;52(2):396-408. https://doi.org/10.1021/ ci200520g; PMid:22201416.

19. Schüürmann G, Ebert RU, Chen J, Wang B, Kühne R. External validation and prediction employing the predictive squared correlation coefficient. Test set activity mean vs training set activity mean. Journal of chemical information and modeling. 2008;48(11):2140-5. https://doi.org/10.1021/ci800253u. PMid:18954136.

20. Consonni V, Ballabio D, Todeschini R. Evaluation of model predictive ability by external validation techniques. Journal of chemometrics. 2010;24(34):194-201. https://doi.org/10.1002/cem.1290.

21. Golbraikh A, Tropsha A. Beware of q2!. J Mol Graph Model 2002; 20: 269276. https://doi.org/10.1016/S1093-3263(01)00123-1. 
Chirico N, Gramatica P. Real external predictivity of QSAR models: how to evaluate it? Comparison of different validation criteria and proposal of using the concordance correlation coefficient. Journal of chemical information and modeling. 2011 Aug 12;51(9):2320-35. https://doi.org/10.1021/ci200211n; PMid:21800825.
23. Zheng, W. Tropsha, A. Novel Variable Selection Quantitative StructureProperty Relationship Approach Based on the k-Nearest Neighbor Principle. J Chem Inf Comput Sci 2000, 40, 185-194. https://doi.org/10.1021/ci980033m; PMid:10661566.

\section{PICTORIAL ABSTRACT}

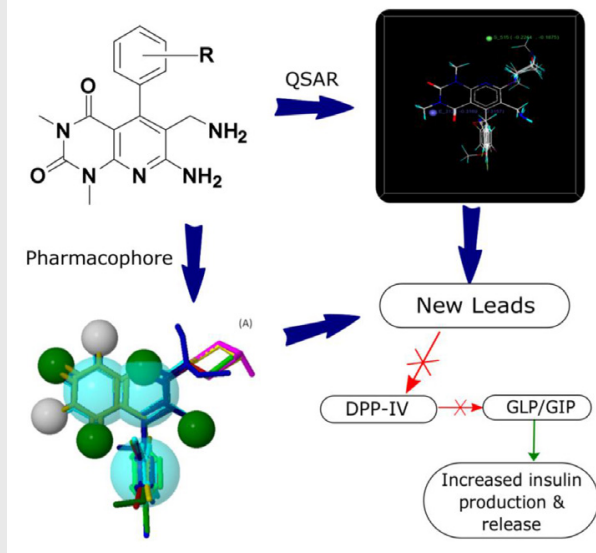

\section{SUMMARY}

1. 3D-QSAR and pharmacophore studies were performed on a series of pyridopyrimidindione derivatives.

2. The result of QSAR analysis shows contribution of electronegative groups and optimum bulk for favourable DPP-IV inhibitory activity.

3. Pharmacophore study envisages the contribution of three $\mathrm{H}$-bond acceptors, one $\mathrm{H}$-bond donor and one aromatic feature for favourable activity.

4. The findings of this study can be explored for improved DPP-IV inhibitory activity.

\section{About Authors}

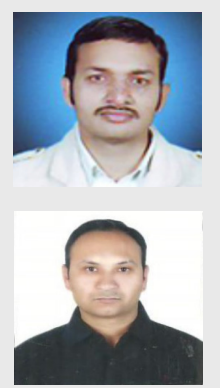

Dr. Sanmati K. Jain: Dr. Sanmati Kumar Jain completed his Master of Pharmacy and Ph.D. from Dr. Hari singh Gour Vishwavidyalaya, Sagar and is Associate Professor at SLT Institute of Pharmaceutical Sciences, GGV, Bilaspur. His research interests include computer aided drug design and synthesis of novel leads for anticancer, antidiabetic, antimicrobial and anti-HIV activities.

Piyush Ghode: Piyush Ghode has completed his Master of Pharmacy in Pharmaceutical Chemistry from IPS Academy, Indore and currently pursuing his Ph.D. from SLT Institute of Pharmaceutical Sciences. His research interests are computer aided drug designing, synthesis and antidiabetic activity of heterocyclic compounds.

Cite this article: Piyush G, Sanmati KJ. Ligand Based in-silico Study on Pyridopyrimidinedione Derivatives as DipeptidyI Peptidase-IV Inhibitors. Indian J of Pharmaceutical Education and Research. 2017;51(4):664-71. 